\title{
Diversity, mobility, and structural and functional evolution of group II introns carrying an unusual 3' extension
}

Nicolas J Tourasse ${ }^{1,2^{*}+}$, Fredrik B Stabell ${ }^{1,3+}$ and Anne-Brit Kolstø ${ }^{1}$

\begin{abstract}
Background: Group II introns are widespread genetic elements endowed with a dual functionality. They are catalytic RNAs (ribozymes) that are able of self-splicing and they are also mobile retroelements that can invade genomic DNA. The group II intron RNA secondary structure is typically made up of six domains. However, a number of unusual group II introns carrying a unique extension of 53-56 nucleotides at the 3' end have been identified previously in bacteria of the Bacillus cereus group.
\end{abstract}

Methods: In the present study, we conducted combined sequence comparisons and phylogenetic analyses of introns, host gene, plasmid and chromosome of host strains in order to gain insights into mobility, dispersal, and evolution of the unusual introns and their extension. We also performed in vitro mutational and kinetic experiments to investigate possible functional features related to the extension.

Results: We report the identification of novel copies of group II introns carrying a 3 ' extension including the first two copies in bacteria not belonging to the B. cereus group, Bacillus pseudofirmus OF4 and Bacillus sp. 2_A_57_CT2, an uncharacterized species phylogenetically close to B. firmus. Interestingly, the B. pseudofirmus intron has a longer extension of 70 bases. From sequence comparisons and phylogenetic analyses, several possible separate events of mobility involving the atypical introns could be identified, including both retrohoming and retrotransposition events. In addition, identical extensions were found in introns that otherwise exhibit little sequence conservation in the rest of their structures, with the exception of the conserved and catalytically critical domains $\mathrm{V}$ and $\mathrm{VI}$, suggesting either separate acquisition of the extra segment by different group II introns or a strong selection pressure acting on the extension. Furthermore, we show by in vitro splicing experiments that the $3^{\prime}$ extension affects the splicing properties differently in introns belonging to separate evolutionary branches.

Conclusions: Altogether this study provides additional insights into the structural and functional evolution of unusual introns harboring a $3^{\prime}$ extension and lends further evidence that these introns are mobile with their extension.

Keywords: Group II intron, Unusual extension, Evolution, pXO1-42, Plasmid, Mobility

\section{Background}

Group II introns are genetic elements that are widespread in bacteria and in the organelles of eukaryotes. They are self-splicing catalytic RNAs (ribozymes) that remove themselves from precursor mRNA transcripts and ligate their flanking sequences (exons). Group II

\footnotetext{
* Correspondence: nicolas.tourasse@ibpc.fr

† Contributed equally

'Laboratory for Microbial Dynamics (LaMDa), Department of Pharmaceutical Biosciences, University of Oslo, Oslo, Norway
}

Full list of author information is available at the end of the article introns are also mobile retroelements which can invade genomic DNA sites [1-5]. Splicing can proceed through two major competing pathways, branchpoint or hydrolytic splicing [6-10]. Branchpoint splicing (or branching) involves two transesterification reactions, where the first reaction is initiated by nucleophilic attack on the 5 ' intron-exon junction by the 2' hydroxyl group of a specific bulged adenosine residue (the branchpoint) in domain VI near the 3' end of the intron. In the second reaction, the flanking exons are ligated and a branched intron lariat containing a 2'-5' linkage is released $[1,2,5]$.
C Biomed Central

C 2011 Tourasse et al; licensee BioMed Central Ltd This is an Open Access article distributed under the terms of the Creative Commons Attribution License (http://creativecommons.org/licenses/by/2.0), which permits unrestricted use, distribution, and reproduction in any medium, provided the original work is properly cited. 
The hydrolytic pathway also consists of two steps; in the first step a water molecule acts as the nucleophile, and a linear intron is released after transesterification in the second step. Mobility occurs through reverse-splicing of the intron RNA into DNA and subsequent reverse-transcription by a multifunctional protein encoded by the intron (IEP, intron-encoded protein). Group II introns recognize and insert predominantly into cognate (homologous) intron-less sites in a process called retrohoming. Homing sites cover $\sim 30 \mathrm{bp}$, and during splicing and reverse-splicing base-pairing interactions are made between a subset of these nucleotides (intron-binding sites, IBS, spanning positions -12 to +1 relative to the insertion site) and the complementary motifs in the intron RNA (exon-binding sites, EBS), while the distal regions are recognized by the IEP $[1,2,4]$. In addition, group II introns can insert into non-cognate (ectopic) sites that share partial similarity to the homing site in a process called retrotransposition, which occurs at a much lower frequency. In bacteria, group II introns are also often associated with other mobile genetic elements, such as insertion sequences and plasmids, that act as vectors for horizontal transfer [11-13].

The secondary structure of the group II intron RNA typically consists of six domains (numbered I to VI) that are linked by a network of tertiary interactions, and introns are classified based on structural features and IEP phylogeny [1,2,5,14-16]. However, we identified 15 copies of six unusual and different group II introns that carry a related 53/ 56-nucleotide (nt) extension at the 3' end [17-19]. All these introns were found in bacteria of the Bacillus cereus group, including B. cereus, B. thuringiensis, B. mycoides, and B. pseudomycoides. These bacterial species are genetically closely related and are known to harbor a range of mobile elements such as plasmids and introns [13,20-23]. Functional analysis demonstrated that the extra segment is part of the intron RNA molecule and affects the self-splicing reaction in vitro, and thus could be considered as a domain VII $[17,18,24]$. Phylogenetic analysis revealed that the unusual introns belong to two subgroups $\alpha$ and $\beta$ within the bacterial $\mathrm{B}$ class $[17,18]$. In the present study we report the identification of the first introns with a 3' extension in bacterial species from outside the $B$. cereus group. Using the complete and diverse set of introns with an extra segment we conducted a detailed sequence and phylogenetic analysis of the introns together with their host genes and strains in order to gain insight into mobility, dispersal, and evolution of these elements and their domain VII. Functional studies were also carried out to investigate possible features related to the extension.

\section{Results and discussion}

Sequence similarity searches of public sequence databases using BLASTN conducted in the present study revealed six additional group II introns carrying a 3' extension similar to those previously identified in refs $[19,17]$, and [18] (Table 1). Interestingly, while all introns with a 3 ' extension known to date were found in closely related bacteria forming the $B$. cereus group, two of the newly discovered elements are encoded by strains of unrelated species, namely Bacillus pseudofirmus OF4 (previously classified as B. firmus OF4; [25]) and the uncharacterized Bacillus sp. 2_A_57_CT2. Phylogenetic analysis based on $16 \mathrm{~S}$ ribosomal DNA sequences indicated that B. sp. 2_A_57_CT2 is close to B. firmus and that B. sp. 2_A_57_CT2, B. pseudofirmus OF4, and the $B$. cereus group are distantly related among the Bacilli (Additional file 1: Figure S1; [26]). These findings therefore extend the distribution of introns carrying an extra domain from the B. cereus group to the Bacilli.

\section{Indirect evidence for mobility of the unusual introns with their extension}

With respect to the phylogeny of the introns themselves, many of the introns with a 3' extension belong to the $\beta$ subgroup within the bacterial B class $[17,18]$, and in particular eight are highly similar to the B.th.I6 intron from B. thuringiensis kurstaki BGSC 4D1/HD1 (Table 1). The B.th.I6-like introns (B.th.I6 and B.c.I16) are all inserted in the same homing site within the pXO1-42 plasmid gene, and the two intron copies (B.th.I6a and b) found in B. thuringiensis kurstaki BGSC 4D1/HD1 were suggested to be the result of intron mobility $[17,18]$. Here, by combining all the available sequence data, supplemented by a PCR screen for pXO1-42, and by using the high sequence similarity between the introns and between the host genes, together with reconstructions of the phylogenetic relationships of the host genes and host strains, we attempted to detect further signs of intron mobility and to identify the events that have driven the dispersal of the unusual introns.

Altogether, the dataset included pXO1-42 sequences for 40 strains, including 12 sequenced large plasmids (180-560 kb) belonging to the "pXO1-like" family [28]. Phylogenetic analysis of the pXO1-42 sequences revealed interesting patterns. Firstly, the pXO1-42 phylogeny was largely inconsistent with the chromosomal MLST phylogeny (Figure 1), which indicates that there has been extensive horizontal transfer of "pXO1-like" plasmids disseminating this gene within the B. cereus group. Indeed, large plasmids are the main vectors of group II intron spread in this bacterial group [13]. Secondly, the pXO1-42 sequences were divided into two clusters separated by a long evolutionary branch and supported by a high statistical value (Figure 1A). This division is further supported by comparison of full plasmid or genome sequences, which confirmed that it corresponds to two groups of plasmids within the "pXO1- 
Table 1 Currently identified group II introns carrying a domain VII

\begin{tabular}{|c|c|c|c|c|}
\hline${\underset{\mathrm{I}}{\text { Intron }}}^{\#,}$ & $\begin{array}{l}\text { Intron copy, Strain, Genbank } \\
\text { accession number, Genomic } \\
\text { coordinates }\end{array}$ & Intron's host gene predicted product & $\begin{array}{l}\text { Phylogenetic } \\
\text { subgroup within } \\
\text { the B class }\end{array}$ & Reference \\
\hline B.c.l4 & $\begin{array}{l}\text { a, B. cereus ATCC 10987 (plasmid } \\
\text { pBc10987), AE017195, 35608-32766 } \\
\text { b, B. cereus AH1271, ACMR01000217, } \\
\text { 14976-17818 } \\
\text { c, B. cereus AH1272, ACMS01000358, } \\
\text { 3111-5953 } \\
\text { d, B. cereus AH1273, ACMT01000367, } \\
\text { 57936-55094 }\end{array}$ & pXO1-70; hypothetical protein with DNA primase domain & $\alpha$ & {$[18,19]$} \\
\hline B.th.15 & $\begin{array}{l}\text { a, B. thuringiensis kurstaki BGSC 4D1/ } \\
\text { HD1, FM992108, 131-3040/Contig365, } \\
4502-7411^{\$} \\
\text { b, B. thuringiensis chinensis CT-43 } \\
\text { (plasmid pCT281), CP001910, 188422- } \\
191331\end{array}$ & pXO1-08; hypothetical protein with two helicase domains & $\beta$ & $\begin{array}{l}\text { [17], This } \\
\text { study }\end{array}$ \\
\hline B.th.16 & $\begin{array}{l}\text { a, B. thuringiensis kurstaki BGSC 4D1/ } \\
\text { HD1, FM992109, 370-3180/Contig355, } \\
4481-1671^{\text {\$ }} \\
\text { b, B. thuringiensis kurstaki BGSC 4D1/ } \\
\text { HD1, FM992110, 363-3174/Contig362, } \\
\text { 5366-2555 } \\
\text { c, B. thuringiensis thuringiensis ATCC } \\
\text { 10792, ACNF01000191, 9655-12466 } \\
\text { d, B. thuringiensis thuringiensis T01001, } \\
\text { ACNA01000143, 13593-10782 } \\
\text { e, B. thuringiensis huazhongensis BGSC } \\
\text { 4BD1, } \\
\text { ACNI01000192, 17280-20089 } \\
\text { f, B. thuringiensis chinensis CT-43 } \\
\text { (plasmid pCT281), CP001910, 139432- } \\
\text { 142243 }\end{array}$ & $\begin{array}{l}\text { pXO1-42; annotated as a protein belonging to the TraG/TraD } \\
\text { family of plasmid proteins involved in bacterial conjugation, } \\
\text { however, shows higher though weak homology to proteins of } \\
\text { type IV secretion systems of the VirBNirD family (see [27]). }\end{array}$ & $\beta$ & $\begin{array}{l}{[17,18] \text {, }} \\
\text { This study }\end{array}$ \\
\hline B.c.l16 & $\begin{array}{l}\text { a, B. cereus Q1 (plasmid pBc239), } \\
\text { CP000228, 228934-231746 } \\
\text { b/c, B. cereus F65185, ACMO01000152, } \\
\text { 2812-1 }\end{array}$ & same as B.th.16 & $\beta$ & {$[18]$} \\
\hline B.th.17 & $\begin{array}{l}\text { a, B. thuringiensis kurstaki BGSC 4D1/ } \\
\text { HD1, FM992111, 1064-3765/Contig366, } \\
\text { 3308-6009 } \\
\text { b, B. thuringiensis kurstaki BGSC 4D1/ } \\
\text { HD1, Contig373, 943-1 + Contig381, } \\
\text { 105890-104869s } \\
\text { c, B. thuringiensis chinensis CT-43 } \\
\text { (plasmid pCT281), CP001910, 105318- } \\
102617\end{array}$ & $\begin{array}{l}\text { hypothetical protein (B.th.17a and c) } \\
\text { nucleoside transporter, NupC family (B.th.17b) }\end{array}$ & $\alpha$ & $\begin{array}{l}\text { [17], This } \\
\text { study }\end{array}$ \\
\hline B.my.11 & $\begin{array}{l}\text { B. mycoides Rock1-4, ACMV01000578, } \\
\text { 1-2843 }\end{array}$ & not known due to missing sequence & $\beta$ & {$[18]$} \\
\hline B.ps.11 & $\begin{array}{l}\text { B. pseudomycoides DSM 12442, } \\
\text { ACMX01000035, 32580- } \\
35423\end{array}$ & intron inserted in non-coding region & $\beta$ & {$[18]$} \\
\hline B.psf.l1 & $\begin{array}{l}\text { B. pseudofirmus OF4 (plasmid pBpOF4- } \\
\text { 01), CP001879, } \\
\text { 172131-169323 }\end{array}$ & DNA primase & $\beta$ & This study \\
\hline Ba.sp.12 & $\begin{array}{l}\text { B. sp. 2_A_57_CT2, ACWD01000076, } \\
\text { 51450-54202 }\end{array}$ & hypothetical protein & $\alpha$ & This study \\
\hline
\end{tabular}

"The entire nucleotide sequences (IEP-encoding ORF included) of B.c.14a, b, c, and d are identical and inserted in the corresponding host gene. B.th.I5a and b differ at three nucleotide positions only. B.th.16b, $c$, and d are identical to each other, while B.th.16a and e are $98.4 \%$ and $99 \%$ identical to the former introns, respectively, and B.th.16f differs from B.th.16b, c, and d at a single nucleotide position. B.c.116a and b/c are 90\% identical to the various B.th.16 copies. All B.th.16 and B.c.l16 copies are located in the same host gene. Due to missing sequence data, it could not be confirmed whether the B.c.l16 intron is present in one or two copies in the B. cereus F65185 strain. The entire nucleotide sequences of B.th.17a and $c$ are identical. Part of the IEP-encoding ORF sequence of B.th.17b is missing from the genomic data, whereas the ribozyme sequence is complete and identical to that of B.th.17a and c. The entire nucleotide sequences of B.my.I1 and B.ps.I1 are $96.5 \%$ identical

${ }^{\&}$ B.th.16-like intron fragments were recently identified in two B. thuringiensis isolates from Mexico (Genbank accession numbers JF800177 and JF800178) \$Information in italics is based on sequence data from the Microgen website http://www.micro-gen.ouhsc.edu/b_thuring/b_thuringiensis_home.htm. Genome assembly from May 3, 2011 


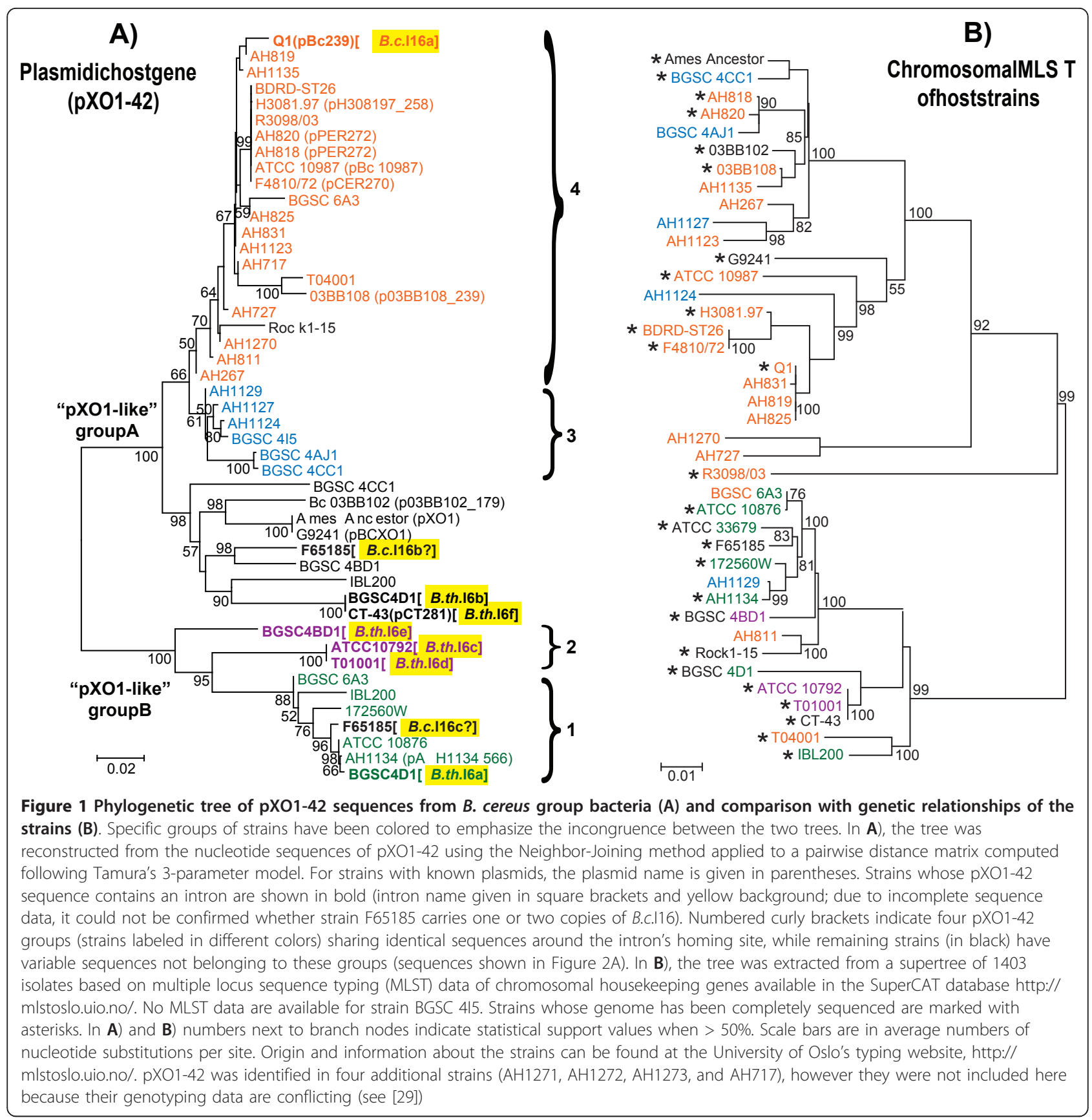

like" family, herein named "A" and "B" (Additional file 1: Figure S2). Thirdly, B.th.I6-like introns are distributed in both groups. Identical copies are present in distantly related pXO1-42 sequences, as exemplified by B.th.I6b and $\mathrm{c} / \mathrm{d}$ and by B.C.I16a and b/c. This strongly suggests mobility of the individual introns rather than transfer of the whole locus containing host gene and intron (Figure 1A). A different example of intron mobility is given by the B. cereus Q1 strain which harbors B.c.I16a. This strain is part of a clonal complex including isolates AH819, AH825, and AH831 that has emerged recently in the MLST supertree (Figure 1B). The latter three isolates encode pXO1-42 sequences closely related to that of Q1 (with an identical homing site) but that are intron-less. This indicates therefore that an independent integration of B.c.I16a must have occurred in B. cereus Q1 quite recently in evolution. A last piece of evidence for mobility of B.th.I6-like introns is given by the fact that the sequence of the B.th.I6/B.c.I16 homing site also correlates with the phylogeny of the full pXO1-42 gene (Figures 1A and 2A). As this sequence interacts with the intron directly by basepairing, the presence of identical 
intron copies in different homing sequences strengthens the idea that this is the result of retrohoming by the introns.

Examination of the insertion sites of the B.th.I7a and $b$ copies indicated that the B.th.I7 intron as well must be mobile with its extension. These two intron copies are inserted in different genes in B. thuringiensis kurstaki BGSC 4D1/HD1 (Table 1) and BLAST sequence similarity searches revealed that the genomic contigs containing B.th.I7a and B.th.I7b matched plasmidic and chromosomal $B$. cereus group sequences, respectively (data not shown). While the nucleotide sequences of the two intron copies are identical, the insertion sites exhibit little similarity, with the exception of the IBS2 motif (Figure 2B). This can be taken as evidence of retrotransposition of B.th.I7 into ectopic sites. This finding, added to the results presented above for the B.th.I6-like introns, shows that both retrohoming and retrotransposition of unusual group II introns in plasmid or chromosomal loci have occurred in B. cereus group genomes. However, no insight into the direction and precise history of these events could be inferred. B.th.I7 and the $B$. th.I6-like introns respectively belong to the $\alpha$ and $\beta$ phylogenetic subgroup within the bacterial B class of group II introns $[17,18]$, indicating that introns from both subgroups are (or have been) intrinsically mobile with their 3' extension.

\section{Identical 3' extensions in divergent introns: independent acquisition or high selection pressure?}

In addition to providing evidence for mobility of the group II introns carrying an extra domain, detailed bioinformatic comparative analysis also revealed features that may be relevant to the structural evolution of these unusual introns. The first major feature is that divergent introns can share identical 3' extensions. This is case for the B.th.I6-like introns, where B.th.I6 from various $B$. thuringiensis strains and B.c.I16 from B. cereus Q1 and F65185 are 90\% identical overall and have identical 54nt extensions (Additional file 1: Figure S3A). Even more remarkable are the related B.my.I1 and B.ps.I1 introns from B. mycoides Rock1-4 and B. pseudomycoides DSM 12442 , respectively, which also share a nearly identical extension with B.th.I6, but are more divergent overall, exhibiting only $60 \%$ nucleotide sequence identity to the B. thuringiensis B.th.I6 intron in domains I-VI (Additional file 1: Figure S3B; note that even though strain Rock1-4 is classified as B. mycoides, it actually belongs

A)

\begin{tabular}{|c|c|c|}
\hline 1 & АTTGTGGATGAATTCCСTGATTATG [ & ] TTGTGCGCCCGTTCA \\
\hline 2 & АTTGTGGATGAGTTCCCGGATTATG [ & ] TTGTGCGCCCGTTCA \\
\hline 3 & АTTGTCGATGAGTTCCCGGATTATG [ & ] TTGTGCGGCCGTTTA \\
\hline 4 & АTTGTCGATGAGTTTCCGGATTACG [ & ]TTGTGCGGC \\
\hline Rock1-15 & АTTGTCGATGAGTTTCCGGATTATG [ & ] TTGTGCGG \\
\hline BGSC $4 \mathrm{D} 1 / \mathrm{CT}-43$ & АTTGTGGATGAGTTCCCGGATTATG [ & ] TTGTTCGG \\
\hline BGSC $4 \mathrm{BD} 1$ & ATTGTGGATGAATTCCCGGATTATG [ & ] TTGTTCGG \\
\hline $03 \mathrm{BB} 102$ & ATTGTCGATGAGTTCCCGGACTATG [ & ] TTGTTCGGC \\
\hline BGSC $\quad 4 \mathrm{CC} 1$ & АTTGTGGATGAGTTCCCAGATTTTG [ & ]TTGTGCGGC \\
\hline IBL 200 & ATTGTCGATGAGTTCCCGGATTTTG [ & ] TTC \\
\hline Ames Ancestor/G9241 & $\pi$ & \\
\hline
\end{tabular}

B)

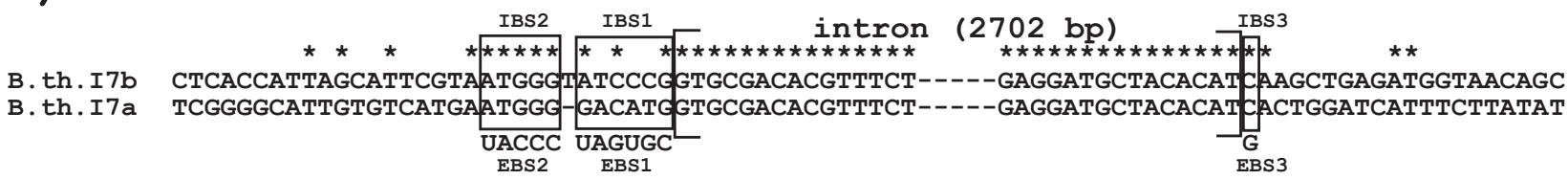

Figure 2 A) Multiple alignment of B.th.16 and B.c.I16 homing sites in pX01-42 sequences. The sequences shown span positions -25 to +15 around the intron insertion site (indicated by square brackets). Sequences numbered 1-4 correspond to the four groups shown in Figure 1A. Strains with different sequences not belonging to these groups (shown in black in Figure 1A) are individually listed by name (strain F65185 is not included due to incomplete sequence data). Nucleotide positions that differ relative to the top sequence are displayed in a black background. B). Insertion sites of the B.th.17a and b intron copies in B. thuringiensis kurstaki BGSC 4D1/HD1. Sites that exhibit identical nucleotides in both sequences are indicated by asterisks. B.th.17a and B.th.17b have identical sequences and are inserted in plasmidic and chromosomal loci, respectively. Intron boundaries are delimited by brackets. The intron binding sites (IBS1, IBS2, and IBS3) in the exons are boxed and their complementary exon binding sites (EBS1, EBS2, and EBS3) in the intron are indicated underneath. The similarity between the insertion sites is weak overall, and is limited to the IBS2 motif, suggesting retrotransposition of B.th.17 into ectopic sites 
to the $B$. pseudomycoides lineage in the $B$. cereus group phylogenetic tree, see [18]). While the B.th.I6, B.c.I16, B. my.I1, and B.ps.I1 introns all belong to the $\beta$ phylogenetic subgroup, there is also a case of an identical extension shared by introns of different subgroups: the 53-nt extension of Ba.sp.I2 from B. sp. A_2_57_CT2 ( $\alpha$ subgroup) is identical to that of B.th.I5 from $B$. thuringiensis BGSC 4D1/HD1 and CT-43 ( $\beta$ subgroup; Additional file 1: Figure S3C). The presence of the same 3' extension in group II introns that otherwise show little conservation overall in the rest of their sequences could suggest that the extension may have been acquired independently by the different introns. Alternatively, as domain VII is important for the self-splicing reaction of the unusual introns [17]; see below), this could imply that there is a very strong selection pressure on the extension for structural and/or functional reasons, as is the case for domains $\mathrm{V}$ (the catalytic center of the ribozyme) and VI (containing the branchpoint), which, like domain VII, are highly conserved in sequence among introns of the B class (Additional file 1: Figure S3; [30]). One may also hypothesize that the conservation of domains V and VI could have favored homologous recombination events that could have mediated the transfer of domain VII between introns that are divergent in the rest of their sequences.

\section{A novel group II intron with a longer 3' extension of 70 nt in B. pseudofirmus}

A second feature relating to the evolution of introns harboring a domain VII is given by the B. pseudofirmus OF4 intron, named B.psf.I1. While the 3' extra segment of all other unusual introns is 53-56 nucleotide long, the extension of B.psf.I1 spans 70 bases (Figure 3$)$. It is predicted to fold into a 2-stem-loop structure (S1 and S2) similar to that of the B. cereus group elements, and, interestingly, the pattern of sequence and structure conservation between the extensions of B.psf.I1 and the B. cereus group introns is the same as that observed previously between the latter introns [17]. That is, first, the small stem S1 is highly conserved in sequence among all the unusual introns, including B.psf.I1. Second, while the S2 stem of B.psf.I1 is somewhat longer than that of the other unusual introns and is not conserved overall, the invariant internal loop representing a putative 11-nt tetraloop receptor motif present in $B$. cereus group introns [17] is identical in sequence in B.psf.I1, and is located at the same relative position within $\mathrm{S} 2$, i.e., $3 \mathrm{bp}$ from the bottom of the stem (Figure 3). This conservation underscores that this motif must be important for intron structure and/or activity, as suggested by mutational analyses which showed that unpairing the $G: C$ pair beneath the internal loop triggered a significant slowdown of the second splicing step [17]. Therefore, although being substantially longer, the 3' extension of the B. pseudofirmus B.psf.I1 intron shares all the features common to that of the other unusual introns and shows that domain VII itself can undergo evolutionary change while maintaining the key features.

\section{The $3^{\prime}$ extension affects the splicing reaction differently in introns from the $\alpha$ and $\beta$ subgroups}

The bioinformatic analyses presented above have given examples of the structural evolution of group II introns carrying a 3' extension. As RNA structure and function are intimately linked, in vitro mutational and kinetic analyses performed using introns belonging to the $\alpha$ and $\beta$ phylogenetic subgroups revealed that these introns also evolved at the functional level. We showed previously that, while the B.c.I4 intron of B. cereus ATCC 10987 ( $\alpha$ subgroup) has adapted to function with the 3' extra domain, the extension was not essential for splicing since the intron could splice nearly as efficiently as wildtype (WT) when the entire extension was deleted [24]. However, the deletion construct (B.c.I4_dS1S2) appeared to produce somewhat more linear form of the intron, suggesting more hydrolytic splicing without the 3 ' extension $[17,24]$. In the present study, we conducted time-course kinetic analyses of the self-splicing of the $B$. c.I4 WT and dS1S2 constructs. These analyses confirmed that the linear form is not the major product of the splicing reaction of WT B.c.I4, even in buffers containing $\mathrm{KCl}$, which is known to promote the hydrolytic splicing pathway [8-10]. In $\mathrm{KCl}$ buffer the linear species only accounted for $\sim 5 \%$ of the intron-containing products after 60 mins, whereas the fraction of free lariat was $\sim 70 \%$ (Figures $4 \mathrm{~B}$ and $5 \mathrm{~B}$ ). In comparison, splicing of the B.c.I4_dS1S2 construct produced a linear and lariat fraction of $\sim 40 \%$ and $\sim 45 \%$, respectively, after the same time period (Figures $4 \mathrm{~A}$ and $5 \mathrm{~B}$ ). These results demonstrate that the 3' extension has a clear impact on the balance between a hydrolytic or transesterification reaction in the first step of splicing. This may imply that the B.c.I4 intron with the 3' extension is either less prone to be hydrolyzed at the $5^{\prime}$ splice site or is more efficient at branching. The bulged branchpoint adenosine in domain VI was therefore removed from the WT and dS1S2 constructs to investigate whether the increased hydrolysis of 5' splice site for dS1S2 could still be observed when there is no competition from this nucleophilic adenosine and the branching pathway. Comparison of the splicing of these two branchpointdeleted mutant constructs, B.c.I4_dA and B.c. I4_dA_dS1S2, showed that the amount of free linear intron produced was very similar (Figures $4 \mathrm{C}$ and $4 \mathrm{D}$ and $5 \mathrm{C}$ ). This suggests that the extension does not affect the rate of hydrolytic splicing directly. A more likely 


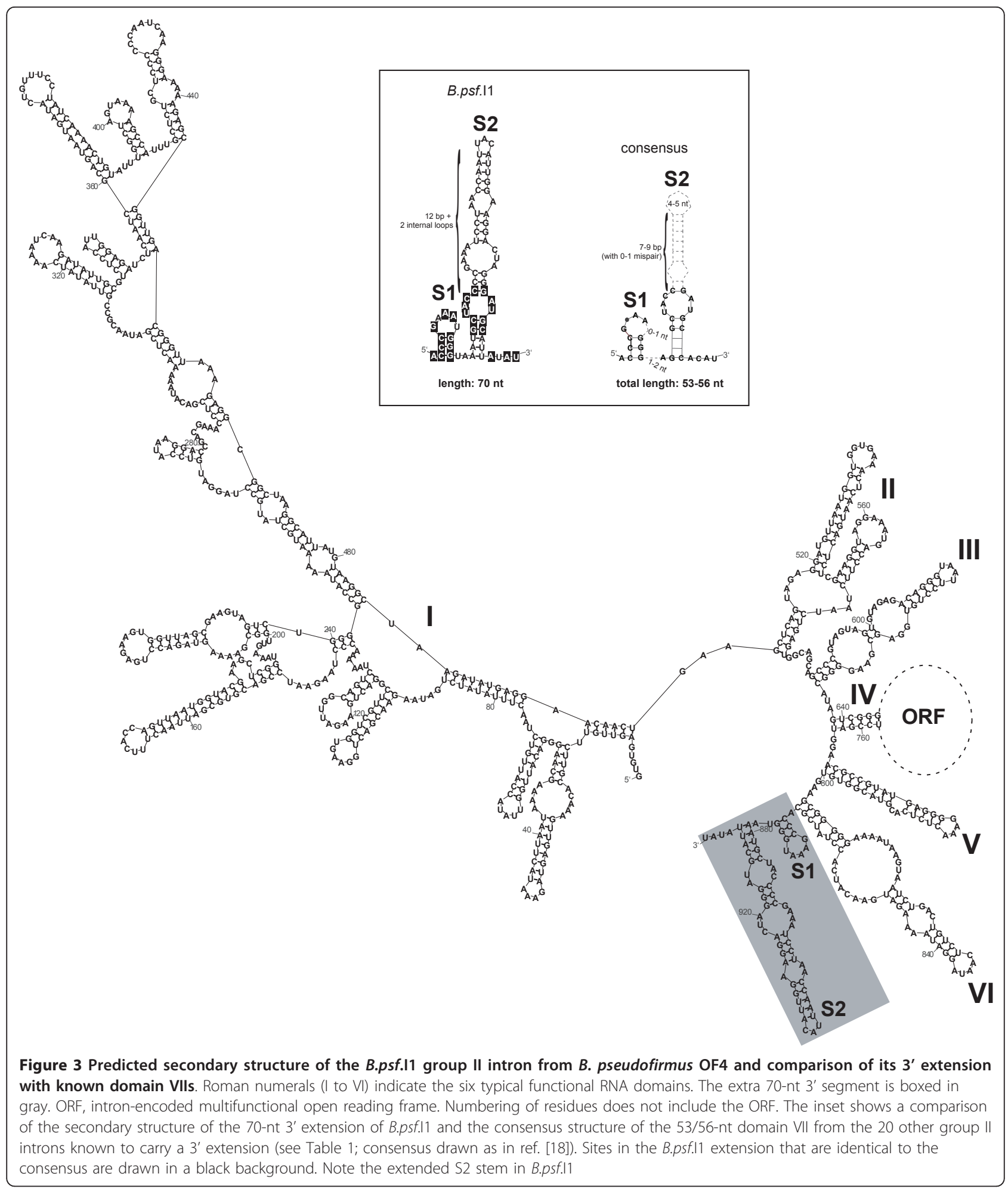

interpretation of the results may be that the 3' extension influences how efficiently domain VI and the branchpoint adenosine are positioned in the catalytic center with the 5' splice site.
Similar splicing experiments were conducted on the $B$. th.I6a intron from $B$. thuringiensis kurstaki BGSC 4D1/ HD1 ( $\beta$ subgroup). Even though splicing of the B.th.I6a construct deleted of the full 54-nt 3' extension (B.th. 


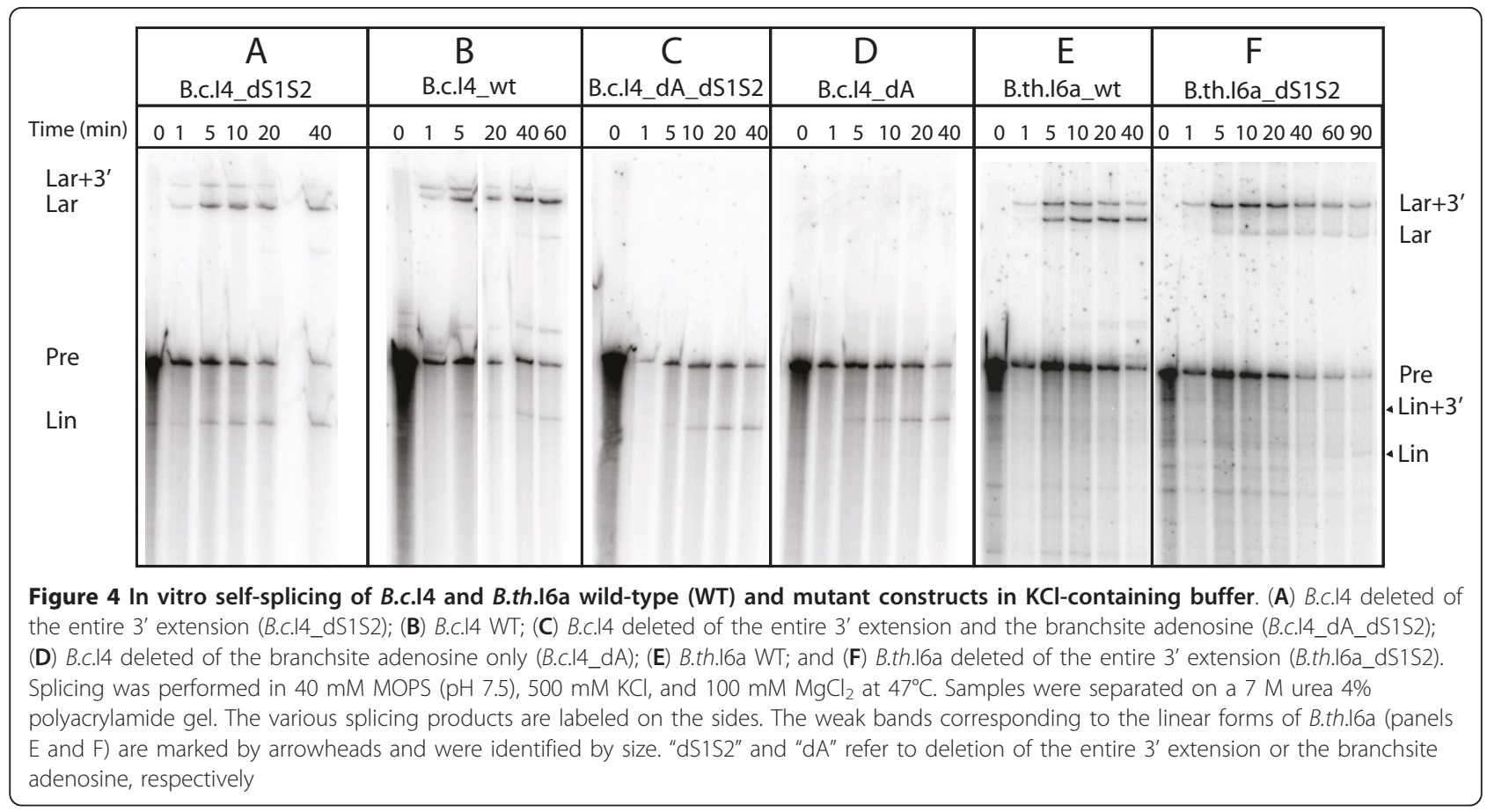

I6a_dS1S2) also appeared to give an increased amount of free linear intron in $\mathrm{KCl}$-containing buffer $(\sim 10 \%$ as opposed to $0 \%$ for WT; see Figures $4 \mathrm{E}$ and $4 \mathrm{~F}$ and $5 \mathrm{D}$ ), in sharp contrast to B.c.I4, splicing of B.th.I6a_dS1S2 in $\left(\mathrm{NH}_{4}\right)_{2} \mathrm{SO}_{4}$ and $\mathrm{KCl}$ buffers showed a dramatic inhibition of the second splicing step. This was revealed by the accumulation of the first step intermediate "lariat + 3' exon" product compared to the B.th.I6a WT construct containing the extension (Figures $4 \mathrm{E}$ and $4 \mathrm{~F}$ and $5 \mathrm{D})$. The strong negative effect on the second splicing step observed for B.th.I6a is remarkable and shows that, unlike B.c.I4, B.th.I6a is dependent on the entire extension for efficient splicing. Together, this functional difference underlines that the two introns have adapted differently to the presence of a similar extension. B.c.I4 and B.th.I6a belong to separate evolutionary branches and exhibit sequence and structural differences that may be the basis for the observed splicing properties related to the extension.

\section{Conclusions}

In conclusion, the sequence, phylogenetic, and experimental data presented in this study have revealed that the group II introns containing a 3' extension and their domain VII have had a dynamic relationship during evolution, both at the structural and functional levels. In addition, the data provided indirect, but clear, evidence that some of the unusual introns must be mobile with their extra segment. Altogether, this warrants structural and functional studies to better understand the structure-function relationship in group II introns carrying a domain VII, and to investigate the role and impact of the 3 ' extension in the mobility reaction.

\section{Methods}

\section{Sequence homology searches}

The nucleotide sequences of the previously identified $B$. cereus group introns carrying a 53/56-nt 3' extension [17-19] were used as queries to search the NCBI Genbank database [31] using BLASTN [32] for additional group II intron ribozymes having a similar extension. BLASTN was run with default parameters, except that the nucleotide match reward was set to $2(-\mathrm{r} 2)$. The genome sequence of $B$. thuringiensis kurstaki HD1 available at the Microgen website (Laboratory for Genomics and Bioinformatics, University of Oklahoma Health Sciences Center, Oklahoma City, USA; http://www. micro-gen.ouhsc.edu/b_thuring/b_thuringiensis_home. htm) was searched as well. Strain HD1 corresponds to strain BGSC 4D1, whose genome has also been sequenced by our laboratory and the Norwegian HighThroughput Sequencing Centre, University of Oslo, Norway (O. A. Økstad and L. Nederbragt, unpublished data). Introns were named following the nomenclature used in the Group II Intron Database [30].

The 86 completely sequenced B. cereus group strains publicly available in Genbank and Microgen at the time of analysis were screened for the B.th.I6 intron's host gene, pXO1-42, using BLAST. The BLAST search was conducted using the pXO1-42 sequence of the pXO1 


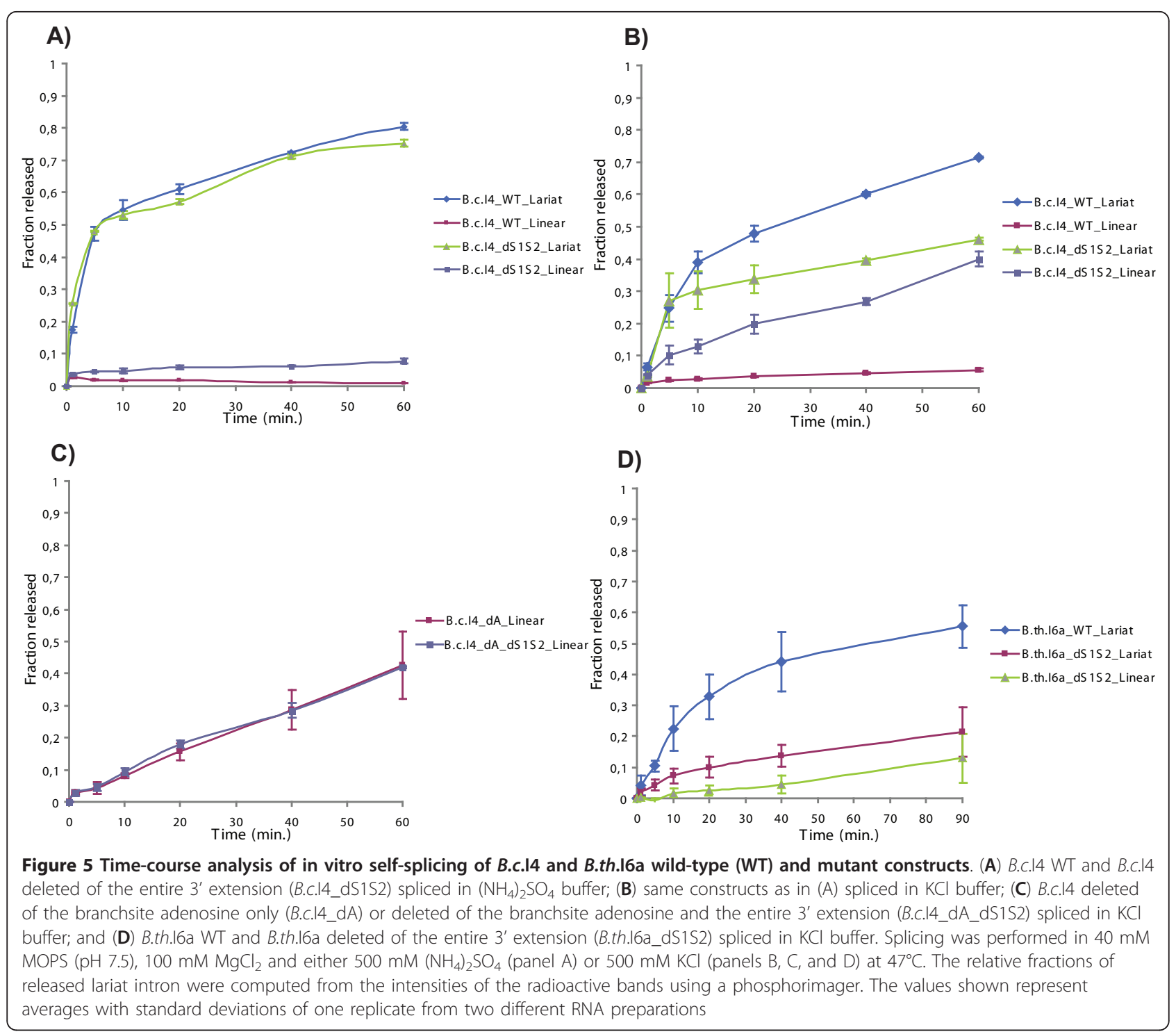

plasmid of B. anthracis Ames Ancestor strain (locus tag GBAA_pXO1_0064) as query, and was performed both at the amino acid and nucleotide levels (run with default parameters, except E-value set to 0.01; -e 0.01).

An additional 36 isolates were screened by PCR, and positive products were sequenced. PCR was performed as previously described using the B.th.I6a_exon_left/ right and B.th.I6b_exon_left/right oligonucleotide primer pairs [17]. Strains covering the phylogenetic diversity of the $B$. cereus group were selected for screening, including strains closely related to those harboring B.th.I6 and the B.th.I6-like B.c.I16 intron, based on the multiple locus sequence typing (MLST) supertree of chromosomal housekeeping genes available in the SuperCAT database at the University of Oslo's typing website ([33,29]; http://mlstoslo.uio.no/).

\section{Secondary structure predictions}

The secondary structures of the B.ps.I1, B.psf.I1, and $B a$. $s p . I 2$ intron RNAs (IEP-encoding ORF removed) were computationally predicted by constrained folding using the MFOLD 3.1 package [34,35] following the consensus structures of group IIB (B class) introns [31,36]. That is, conserved and identifiable sequence motifs corresponding to the consensus structures were forced during the folding computation.

\section{Phylogenetic analyses}

Homologous pXO1-42 nucleotide sequences were aligned using CLUSTALW 2 [37,38], followed by manual corrections done in SEAVIEW 4 [39,40]. A phylogenetic tree based on the multiple alignment was then reconstructed using the Neighbor-Joining method [41] 
applied to a matrix of pairwise distances between sequences. Evolutionary distances were computed according to Tamura's 3-parameter model [42], which takes into account multiple substitutions at a given site, differences between the rates of transitions and transversions, and $\mathrm{G}+\mathrm{C}$ content bias. For strains with completely sequenced genomes or plasmids (marked with asterisks in Figure 1B) the full pXO1-42 sequence $(\sim 3.5$ kb) was used, whereas a partial fragment of only $\sim 400$ bp that includes the homing site of B.th.I6-like introns was available for the strains that were screened by PCR. Thus, sites with gaps were removed in a pairwise manner when computing distances. Statistical support for branches in the tree was assessed by 1000 bootstrap replicates [43]. Phylogenetic analyses were done with MEGA 4.0.2 software [44].

The chromosomal phylogeny of the B. cereus group strains encoding the pXO1-42 gene was reconstructed using the MLST data available in the SuperCAT database ([33,29]; http://mlstoslo.uio.no/). The data included the nucleotide sequences of 7 to 26 chromosomal housekeeping genes, depending on the strain. According to information in culture collections, $B$. thuringiensis kurstaki BGSC 4D1 and ATCC 33679 should be the same strain and both correspond to strain HD1. However, typing studies revealed that the former two strains exhibit genotypic differences $[29,45]$. Thus, the sequence data for strains BGSC 4D1 and ATCC 33679 were included in the phylogeny. A supertree of 1403 B. cereus group isolates was reconstructed using the matrix representation by parsimony (MRP) technique as done in SuperCAT (see [33] for details), and the subtree containing the $40 \mathrm{pXO1-42-encoding} \mathrm{strains} \mathrm{was} \mathrm{extracted}$ from the supertree (pXO1-42 is also present in strains AH1271, AH1272, AH1273, and AH717, however these strains were not included in further analyses because their genotyping data are conflicting, see [29]). In order to obtain branch lengths that are proportional to numbers of nucleotide substitutions, branch lengths in the supertree were recomputed using PHYML $3.0[46,47]$ and the Felsenstein-1984 nucleotide substitution model [48] supplemented with a gamma distribution $(F 84+\Gamma)$. This model allows for unequal base frequencies, transition/transversion rate bias, and gamma-distributed substitution rate variation among sites. Statistical support for branches in the supertree was assessed by approximate likelihood ratio tests with Shimodaira-Hasegawalike support values $[33,46,49]$.

\section{Site-directed mutagenesis}

Site-directed mutagenesis to generate intron constructs B.c.I4_dA, B.c.I4_dA_dS1S2, and B.th.I6a_dS1S2 was performed with Quikchange II (Stratagene) according to the manufacturer's instructions using two complementary oligonucleotides (of $\sim 40$ bases) containing the desired mutation(s) with either B.c.I4 or B.th.I6a $\triangle \mathrm{ORF}$ constructs as templates [17,24]. Primers are listed in Additional File 1: Table S4. Deletion of the 3' extension from B.th.I6a (B.th.I6a_dS1S2 construct) was performed in the same manner as done previously for B.c. I4 (B.c.I4_dS1S2 construct; [24]), i.e., by maintaining the last three nucleotides before the 3' splice site. All constructs were verified by sequencing.

\section{In vitro transcription}

$1 \mu \mathrm{g}$ of plasmid construct was linearized by XhoI for transcription reactions with $30 \mathrm{U}$ T7 RNA polymerase (Ambion) according to the manufacturer's instructions. Transcription and gel-purification of radiolabelled and unlabelled RNA were conducted as previously described [24].

\section{In vitro self-splicing of ribozyme}

In vitro generated transcripts were denatured and refolded using a GenAmp 2700 PCR machine (Applied Biosystems), by incubating the transcripts in $10 \mathrm{mM}$ MOPS, pH 7.5 at $90^{\circ} \mathrm{C}$ for $1 \mathrm{~min}, 75^{\circ} \mathrm{C}$ for $5 \mathrm{~min}$, and then slow cooling to the splicing temperature of $47^{\circ} \mathrm{C}$. Intron transcripts were spliced with $70000 \mathrm{cpm}$ RNA or $\sim 0.1 \mu \mathrm{g}$ unlabelled transcripts in $40 \mathrm{mM}$ MOPS, $\mathrm{pH} 7.5$, $100 \mathrm{mM} \mathrm{MgCl}_{2}$, and either $500 \mathrm{mM}\left(\mathrm{NH}_{4}\right)_{2} \mathrm{SO}_{4}$ or 500 $\mathrm{mM} \mathrm{KCl}$ at $47^{\circ} \mathrm{C}$. Reactions were initiated by adding pre-warmed splicing buffer to the transcript RNA giving a total reaction volume of $40 \mu \mathrm{l}$. At each time point of the time-course analysis, $2 \mu \mathrm{l}$ were taken out, quenched with loading buffer (Ambion) and storing samples on dry ice. Samples were then heated to $95^{\circ} \mathrm{C}$ and cooled on ice, before being separated on a $7.5 \mathrm{M}$ Urea $4 \%$ polyacrylamide gel. Gels were then vacuum dried, exposed, and analyzed using a Molecular Dynamics Storm 860 Phosphorimager.

For subsequent RT-PCR and sequencing of these splicing products, either unlabeled spliced transcripts, purified with Nucleotide purification kit (Qiagen), or labeled spliced transcript species, excised from gels, were used as templates.

For kinetic analysis, the intensities of the radioactive bands were quantified using the ImageQuant 5.0 software. The relative fractions of unspliced precursor and free lariat RNA were computed from the intensities of the radioactive bands of all intron-containing products.

\section{Additional material}

Additional file 1: Figure S1-S3 and Table S4. The file includes three supplementary figures (S1-S3) along with the corresponding legends and associated references. The figures show respectively a phylogenetic tree of Bacillus species (Figure S1), comparisons of sequence homology 
between large plasmids (Figure S2), and drawings of the secondary structure of unusual group II introns (Figure S3). The file also includes a supplementary table (\$4) listing the oligonucleotide primers used for the in vitro splicing experiments.

\section{Acknowledgements}

We thank Ole Andreas Økstad, LaMDa, University of Oslo, and Lex Nederbragt, Norwegian High-Throughput Sequencing Centre http://www. sequencing.uio.no/, University of Oslo, for providing unpublished preliminary genomic sequence data of $B$. thuringiensis kurstaki BGSC 4D1. This work was supported by the Norwegian Functional Genomics (FUGE II) and the Consortium for Advanced Microbial Sciences and Technologies (CAMST) platform of the Research Council of Norway.

\section{Author details}

'Laboratory for Microbial Dynamics (LaMDa), Department of Pharmaceutical Biosciences, University of Oslo, Oslo, Norway. ${ }^{2}$ Institut de Biologie PhysicoChimique, UMR CNRS 7141, Université Pierre et Marie Curie, 13 rue Pierre et Marie Curie, 75005 Paris, France. ${ }^{3}$ GeoKnowledge AS, Oslo, Norway.

\section{Authors' contributions}

NJT and FBS jointly conceived the study and wrote the manuscript. NJT conducted the bioinformatic analyses. FBS performed the laboratory experiments. ABK supervised the study and contributed to the interpretation of the data. All authors have read and approved the current manuscript.

\section{Competing interests}

The authors declare that they have no competing interests.

Received: 10 September 2011 Accepted: 28 December 2011 Published: 28 December 2011

\section{References}

1. Lambowitz AM, Zimmerly S: Mobile group II introns. Annu Rev Genet 2004, 38:1-35

2. Pyle AM, Lambowitz AM: Group II introns: ribozymes that splice RNA and invade DNA. In The RNA world.. third edition. Edited by: Gesteland RF, Cech TR, Atkins JF. Cold Spring Harbor, N.Y.: Cold Spring Harbor Laboratory Press; 2006:469-505, vol. Cold Spring Harbor monograph series 43.

3. Robart AR, Zimmerly S: Group II intron retroelements: function and diversity. Cytogenet Genome Res 2005, 110(1-4):589-597.

4. Toro N, Jimenez-Zurdo JI, Garcia-Rodriguez FM: Bacterial group II introns: not just splicing. FEMS Microbiol Rev 2007, 31(3):342-358.

5. Lehmann K, Schmidt U: Group II introns: structure and catalytic versatility of large natural ribozymes. Crit Rev Biochem Mol Biol 2003, 38(3):249-303.

6. Chin K, Pyle AM: Branch-point attack in group II introns is a highly reversible transesterification, providing a potential proofreading mechanism for 5'-splice site selection. RNA 1995, 1(4):391-406.

7. Chu VT, Liu Q, Podar M, Perlman PS, Pyle AM: More than one way to splice an RNA: branching without a bulge and splicing without branching in group II introns. RNA 1998, 4(10):1186-1202.

8. Daniels DL, Michels WJ Jr, Pyle AM: Two competing pathways for selfsplicing by group II introns: a quantitative analysis of in vitro reaction rates and products. J Mol Biol 1996, 256(1):31-49.

9. Jarrell KA, Peebles CL, Dietrich RC, Romiti SL, Perlman PS: Group II intron self-splicing. Alternative reaction conditions yield novel products. J Biol Chem 1988, 263(7):3432-3439.

10. Peebles $C L$, Benatan EJ, Jarrell KA, Perlman PS: Group II intron self-splicing: development of alternative reaction conditions and identification of a predicted intermediate. Cold Spring Harb Symp Quant Biol 1987, 52:223-232.

11. Dai L, Zimmerly S: Compilation and analysis of group II intron insertions in bacterial genomes: evidence for retroelement behavior. Nucleic Acids Res 2002, 30(5):1091-1102.

12. Klein JR, Dunny GM: Bacterial group II introns and their association with mobile genetic elements. Front Biosci 2002, 7:d1843-d1856.
13. Tourasse NJ, Kolstø AB: Survey of group I and group II introns in 29 sequenced genomes of the Bacillus cereus group: insights into their spread and evolution. Nucleic Acids Res 2008, 36(14):4529-4548.

14. Dai L, Chai D, Gu SQ, Gabel J, Noskov SY, Blocker FJ, Lambowitz AM, Zimmerly S: A three-dimensional model of a group II intron RNA and its interaction with the intron-encoded reverse transcriptase. Mol Cell 2008, 30:1-14.

15. Toor N, Keating KS, Taylor SD, Pyle AM: Crystal structure of a self-spliced group II intron. Science 2008, 320(5872):77-82

16. Pyle AM: The tertiary structure of group II introns: implications for biological function and evolution. Crit Rev Biochem Mol Biol 2010, 45(3):215-232

17. Stabell FB, Tourasse NJ, Kolst $\varnothing A B$ : A conserved $3^{\prime}$ extension in unusual group II introns is important for efficient second-step splicing. Nucleic Acids Res 2009, 37(10):3202-3214.

18. Tourasse NJ, Stabell FB, Kolstø AB: Structural and functional evolution of group II intron ribozymes: insights from unusual elements carrying a $3^{\prime}$ extension. N Biotechnol 2010, 27(3):204-211.

19. Tourasse NJ, Stabell FB, Reiter L, Kolstø AB: Unusual group II introns in bacteria of the Bacillus cereus group. J Bacteriol 2005, 187(15):5437-5451.

20. Helgason E, Økstad OA, Caugant DA, Johansen HA, Fouet A, Mock M, Hegna I, Kolsto AB: Bacillus anthracis, Bacillus cereus, and Bacillus thuringiensis-one species on the basis of genetic evidence. Appl Environ Microbiol 2000, 66(6):2627-2630

21. Kolstø AB, Tourasse NJ, Økstad OA: What sets Bacillus anthracis apart from other Bacillus species? Annu Rev Microbiol 2009, 63:451-476.

22. Rasko DA, Altherr MR, Han CS, Ravel J: Genomics of the Bacillus cereus group of organisms. FEMS Microbiol Rev 2005, 29(2):303-329.

23. Tourasse NJ, Helgason E, Økstad OA, Hegna IK, Kolstø AB: The Bacillus cereus group: novel aspects of population structure and genome dynamics. J Appl Microbiol 2006, 101(3):579-593.

24. Stabell FB, Tourasse NJ, Ravnum S, Kolstø AB: Group II intron in Bacillus cereus has an unusual $3^{\prime}$ extension and splices 56 nucleotides downstream of the predicted site. Nucleic Acids Res 2007, 35(5):1612-1623.

25. Takami H, Krulwich TA: Reidentification of facultatively alkaliphilic Bacillus firmus OF4 as Bacillus pseudofirmus OF4. Extremophiles 2000, 4(1):19-22.

26. Goto K, Omura T, Hara Y, Sadaie Y: Application of the partial $16 \mathrm{~S}$ rDNA sequence as an index for rapid identification of species in the genus Bacillus. J Gen Appl Microbiol 2005, 46(1):1-8.

27. Grynberg M, Li Z, Szczurek E, Godzik A: Putative type IV secretion genes in Bacillus anthracis. Trends Microbiol 2007, 15(5):191-195.

28. Rasko DA, Rosovitz MJ, Økstad OA, Fouts DE, Jiang L, Cer RZ, Kolstø $A B$, Gill SR, Ravel J: Complete sequence analysis of novel plasmids from emetic and periodontal Bacillus cereus isolates reveals a common evolutionary history among the B. cereus-group plasmids, including Bacillus anthracis pXO1.J Bacteriol 2007, 189(1):52-64.

29. Tourasse NJ, Økstad OA, Kolstø AB: HyperCAT: an extension of the SuperCAT database for global multi-scheme and multi-datatype phylogenetic analysis of the Bacillus cereus group population. Database (Oxford) 2010, 2010, baq017.

30. Dai L, Toor N, Olson R, Keeping A, Zimmerly S: Database for mobile group II introns. Nucleic Acids Res 2003, 31(1):424-426.

31. Benson DA, Karsch-Mizrachi I, Lipman DJ, Ostell J, Sayers EW: GenBank. Nucleic Acids Res 2011, , 39 Database: D32-D37.

32. Altschul SF, Madden TL, Schaffer AA, Zhang J, Zhang Z, Miller W, Lipman DJ: Gapped BLAST and PSI-BLAST: a new generation of protein database search programs. Nucleic Acids Res 1997, 25(17):3389-3402.

33. Tourasse NJ, Kolstø AB: SuperCAT: a supertree database for combined and integrative multilocus sequence typing analysis of the Bacillus cereus group of bacteria (including B. cereus, B. anthracis and $B$. thuringiensis). Nucleic Acids Res 2008, 36 Database: D461-D468.

34. Zuker M: Mfold web server for nucleic acid folding and hybridization prediction. Nucleic Acids Res 2003, 31(13):3406-3415.

35. Markham NR, Zuker M: UNAFold: software for nucleic acid folding and hybridization. Methods Mol Biol 2008, 453:3-31.

36. Toor N, Hausner G, Zimmerly S: Coevolution of group II intron RNA structures with their intron-encoded reverse transcriptases. RNA 2001, 7(8):1142-1152.

37. Larkin MA, Blackshields G, Brown NP, Chenna R, McGettigan PA, McWilliam H, Valentin F, Wallace IM, Wilm A, Lopez R, et al: Clustal W and Clustal $\times$ version 2.0. Bioinformatics 2007, 23(21):2947-2948. 
38. Thompson JD, Higgins DG, Gibson TJ: CLUSTAL W: improving the sensitivity of progressive multiple sequence alignment through sequence weighting, position-specific gap penalties and weight matrix choice. Nucleic Acids Res 1994, 22(22):4673-4680.

39. Gouy M, Guindon S, Gascuel O: SeaView version 4: a multiplatform graphical user interface for sequence alignment and phylogenetic tree building. Mol Biol Evol 2010, 27(2):221-224.

40. Galtier N, Gouy M, Gautier C: SEAVIEW and PHYLO_WIN: two graphic tools for sequence alignment and molecular phylogeny. Comput App! Biosci 1996, 12(6):543-548.

41. Saitou N, Nei M: The neighbor-joining method: a new method for reconstructing phylogenetic trees. Mol Biol Evol 1987, 4(4):406-425.

42. Tamura K: Estimation of the number of nucleotide substitutions when there are strong transition-transversion and $\mathrm{G}+\mathrm{C}$-content biases. Mol Biol Evol 1992, 9(4):678-687.

43. Felsenstein J: Confidence limits on phylogenies: an approach using the bootstrap. Evolution 1985, 39:783-791.

44. Tamura K, Dudley J, Nei M, Kumar S: MEGA4: Molecular Evolutionary Genetics Analysis (MEGA) software version 4.0. Mol Biol Evol 2007, 24(8):1596-1599.

45. Hill KK, Ticknor LO, Okinaka RT, Asay M, Blair H, Bliss KA, Laker M, Pardington PE, Richardson AP, Tonks $\mathrm{M}$, et al: Fluorescent amplified fragment length polymorphism analysis of Bacillus anthracis, Bacillus cereus, and Bacillus thuringiensis isolates. Appl Environ Microbiol 2004, 70(2):1068-1080

46. Guindon S, Dufayard JF, Lefort V, Anisimova M, Hordijk W, Gascuel O: New algorithms and methods to estimate maximum-likelihood phylogenies: assessing the performance of PhyML 3.0. Syst Biol 2010, 59:307-321.

47. Guindon S, Gascuel O: A simple, fast, and accurate algorithm to estimate large phylogenies by maximum likelihood. Syst Biol 2003, 52(5):696-704.

48. Felsenstein J, Churchill GA: A hidden markov model approach to variation among sites in rate of evolution. Mol Biol Evol 1996, 13(1):93-104.

49. Anisimova M, Gascuel O: Approximate likelihood-ratio test for branches: a fast, accurate, and powerful alternative. Syst Biol 2006, 55(4):539-552.

doi:10.1186/1756-0500-4-564

Cite this article as: Tourasse et al:: Diversity, mobility, and structural and functional evolution of group II introns carrying an unusual $3^{\prime}$ extension. BMC Research Notes 2011 4:564.

\section{Submit your next manuscript to BioMed Central and take full advantage of:}

- Convenient online submission

- Thorough peer review

- No space constraints or color figure charges

- Immediate publication on acceptance

- Inclusion in PubMed, CAS, Scopus and Google Scholar

- Research which is freely available for redistribution

Submit your manuscript at www.biomedcentral.com/submit 